\title{
Quality Of Life of Laryngeal Carcinoma Patients after Total Laryngectomy
}

\author{
Achmad Prihadianto, Yussy Afriani Dewi, Agung Dinasti Permana \\ Department of Otorhinolaryngology-Head \& Neck Surgery, Faculty of Medicine \\ Universitas Padjadjaran/Dr. Hasan Sadikin General Hospital Bandung Indonesia
}

\begin{abstract}
Background: Management of laryngeal carcinoma has been widely developed, either by surgery, radiotherapy, and/or chemotherapy. The treatment has a major impact on physical, social, and psychological health that can change the quality of life of patients. This study aimed to determine the quality of life of laryngeal carcinoma patients after total laryngectomy.

Methods: This descriptive study was conducted from May to August 2018. Patients with post total laryngectomy at the Division of Ear, Nose, Throat, Head and Neck Surgery, Dr. Hasan Sadikin General Hospital, Bandung were recruited. Short Form 36 (SF-36) Study Questionnaire and the European Organization for Research and Treatment of Cancer Head and Neck Cancer Quality of Life Questionnaire (EORTC QLQ-H \& N35) were used, and data were presented in the form of descriptive narratives and tables.

Results: In total, 23 patients were included consisting of 19 men (82.61\%) and women (17.39\%), aged 56-65 years old. The mean score of quality of life in physical components of SF-36 was $87.55 \pm 2.35$ and in mental components was $85.35 \pm 3.92$. The highest score of quality of life of EORTC QLQ-H \& N35 on the speech problem scale was $51.69 \pm 6.36$.

Conclusion: The quality of life of laryngeal carcinoma patients after total laryngectomy is generally good, however, speech is the main problem and needs to be further elaborated to enhance the quality of life.
\end{abstract}

Keywords: Laryngeal carcinoma, total laryngectomy, quality of life

\section{Introduction}

Laryngeal carcinoma is a malignancy in the larynx which affects the supraglottic, glottic, and subglottic regions. ${ }^{1}$ The therapeutic modalities of laryngeal carcinoma have developed, for example by surgery, radiation, chemotherapy, or a combination there of.

In patients who have had total laryngectomy procedure, the ability of the larynx to produce sound will disappear, and adaptation to this situation is needed. On the other hand, swallowing and breathing process are also affected. Therefore, treatment of laryngeal carcinoma has a major impact on physical, social, and physiological health that may change the quality of life. ${ }^{2}$ Quality of life is one of the main concerns in the head and neck cancer treatment. ${ }^{3}$ It is important to evaluate the quality of life in patients who have total laryngectomy.

Quality of life is one of the main concerns of head and neck oncology. There are several questionnaires to assess the quality of life among patients after having surgery of the larynx, known as post laringectomy. Short Form 36 (SF-36) Study Questionnaire is used as a measurement tool to assess the quality of life of patients in general, whereas the European Organization for Research and Treatment of Cancer Head and Neck Cancer Quality of Life Questionnaire (EORTC QLQ-H \& N35) measure a specific questionnaire to assess aspects of quality of life in patients with head and neck cancer. The combination of the two questionnaires is expected to better illustrate the quality of life in patients with head and neck cancer, especially can add more specific components of quality of life that are not found in the general questionnaire. ${ }^{5,6}$

This study aimed to determine the quality of life of laryngeal carcinoma patients after total laryngectomy, including all aspects related to laryngeal function in patients with laryngeal carcinoma.

Correspondence: Achmad Prihadianto, Department of Otorhinolaryngology-Head \& Neck Surgery, Faculty of Medicine Universitas Padjadjaran/Dr. Hasan Sadikin General Hospital, Jl. Pasteur 38 Bandung, Email: akmaleb20@gmail.com 


\section{Methods}

This descriptive study was conducted from Mei to Agustus 2018. All patients in that period with post total laryngectomy in the Department of Otorhinolaryngology-Head and Neck Surgery Dr. Hasan Sadikin General Hospital, Bandung were included. The inclusion criteria were patients with total laryngectomy within 3 months or more after radiotherapy without any other complications and comorbidities. Ethical clearance was obtained from the Ethical Committee of Dr. Hasan Sadikin General Hospital.

In brief, data was taken through the interviewing process using Short Form 36 (SF36) Study Questionnaire and the European Organization for Research and Treatment of Cancer Head and Neck Cancer Quality of Life Questionnaire (EORTC QLQ-H \& N35). SF36 questionnaire consisted of 36 questions consisting of two major components, physical and mental components. Physical components consist of physical health, activity restrictions due to physical health, body pain, and perceptions of general health. The mental componentconsists of activity restrictions due to emotional problems, vitality, mental health, and social function. The score of each question was numerical with a scale of $0-100$. A score of 0 indicated a low health level and a score of 100 indicates the healthiest level. The scores were further averaged from the question that has the same dimensions. ${ }^{4,5}$ EORTC QLQ-H \& N35 consists of 35 questions; divided into 7 major scales including pain, swallowing problems, sensory problems, speech problems, eating problem, social interaction, and sexual problems and 11 minor scales consisting of dental problems, mouth opening problems, dry mouth thick spit, cough, feeling sick, use of pain killer, use of nutritional supplements, use of nasogastric tube, weight loss, weight gain. The first questions were assessed on a 4 Likert scale (never, rarely, enough, often) while the remaining 5 questions were assessed by a dichotomous scale (yes, no). The final score was interpreted in range of values from 0 to 100. The higher results indicated the increase in health problems and the decrease in the quality of life. ${ }^{6}$

The collected data were processed with a scoring system and analyzed through the Statistical Package for Social Sciences (SPSS)

Table 1 Characteristics of Research Subjects

\begin{tabular}{lcc}
\hline \multicolumn{1}{c}{ Variable } & Amount (n=23) & Percentage (\%) \\
\hline Stage & & - \\
Stage I & - & - \\
Stage II & 9 & 39.13 \\
Stage III & 14 & 60.86 \\
Stage IV & & \\
Gender & 19 & 82.61 \\
Male & 4 & 17.39 \\
Female & & \\
Age & 1 & 4.35 \\
$\leq 45$ years & 3 & 13.04 \\
$46-55$ years & 15 & 65.22 \\
$56-65$ years & 4 & 17.39 \\
$\geq 66$ years & & \\
Last Education & 1 & 4.35 \\
Elementary School & 4 & 17.39 \\
Junior High School & 16 & 69.57 \\
Senior High School & 2 & 8.70 \\
University & &
\end{tabular}


program version 23.0. To assess the normality of the data, this study used Shapiro-Wilktest. Univariate data analysis on categorical variables were used to see the proportion of each variable that would be presented descriptively, while the numeric variables were represented by mean, standard deviation, and median. Data were presented in the form of descriptive narratives with tables and/or graphs.

\section{Results}

In total, 23 post laryngectomy patients were included, consisting of patients with laryngeal carcinoma of stage III (n 9; 39.13\%) and stage IV (n 14; 60.86\%) and the clinical characteristics of those patients were presented in Table1. Most of the patients were male (n 19; 82.61\%), predominantly in the range age of 56-65 years old.

The total score of the SF-36 questionnaire showed good result, consisting of a physical component with a mean score of $87.55+2.35$ and mental component with a mean score of 85.35+3.92. Scoring on the EORTC QLQ-H \& N35 questionnaire had a range of values from 0 to 100. The higher results explained the increasing number of health problems and the quality of life of patients decrease. The highest scoring score was found in the speech problems, weight gain, use of nutritional supplements, use of painkiller, and coughing.
A low score was observed on the scale of pain, swallowing problems, sensory problems, eating problems, social interactions, sexual problems, dental problems, problems with opening wide mouths, dry mouth, thick spit, use of the nasogastric tube and weight loss.

The pain scale was lower but the pain killer consumption was quite high, possibly because patients used drug stalls. The average value of weight gain in patients with post laringectomy and radiotherapy interviewed using a questionnaire was 47.83 because no swallowing problem was observed in the patients. The average value of nutritional supplement use in patients interviewed used a questionnaire of 34.78 because patients were still taking nutritional supplements given by their closest family in hopes of better health. None of the patients had used the gastric tube.

\section{Discussions}

This study was involving patients who underwent a total laryngectomy because of laryngeal carcinoma stage III and IV. Dr. Hasan Sadikin Hospital is a Level III referral hospital, thus, the patients who come are mostly at an advanced stage. The definitive therapy for advanced cancer is a combination therapy of surgery with radiotherapy or chemoradiotherapy. The surgical options that can be done are transoral resection using a laser, partial laryngectomy, and total

Table 2 Mean Values of SF-36 Components in Patients with Laryngeal Carcinoma Post Total Laryngectomy

\begin{tabular}{lc}
\hline \multicolumn{1}{c}{ Component } & Mean \pm Standard Deviation \\
\hline Physical component & \\
Physical health & $92.17 \pm 6.25$ \\
Activity restrictions due to physical health & $95.65 \pm 3.55$ \\
Body pain & $84.13 \pm 7.07$ \\
Perceptions of general health & $78.26 \pm 9.22$ \\
Total score in the physical component & $87.55 \pm 2.35$ \\
Mental component & \\
Activity restrictions due to emotional problems & $86.96 \pm 11.50$ \\
Vitality & $81.52 \pm 2.50$ \\
Mental health & $84.87 \pm 7.69$ \\
Social function & $88.04 \pm 4.61$ \\
Total score in the mental component & $85.35 \pm 3.92$ \\
Total score & $86.5 \pm 2.99$ \\
\hline
\end{tabular}


Table 3 Mean Values of EORTC QLQ-H \& N35 in Patients with Laryngeal Carcinoma after Total Laryngectomy

\begin{tabular}{lcc}
\hline \multicolumn{1}{c}{ Scale } & Mean & Standard Deviation \\
\hline Pain & 5.43 & 9.27 \\
Swallowing problems & 3.99 & 7.48 \\
Sensory problems & 2.17 & 5.74 \\
Speech problems & 51.69 & 6.36 \\
Eating problem & 4.71 & 7.46 \\
Social interaction & 9.28 & 11.50 \\
Sexual problems & 0.72 & 3.48 \\
Dental problems & 2.90 & 9.60 \\
Mouth opening problems & 7.25 & 14.06 \\
Dry mouth & 2.90 & 9.60 \\
Thick spit & 7.25 & 14.06 \\
Cough & 26.09 & 14.06 \\
Feeling sick & 10.14 & 15.68 \\
Use of pain killer & 26.09 & 44.90 \\
Use of nutritional supplements & 34.78 & 48.70 \\
Use of nasogastric tube & - & - \\
Weight loss & 8.70 & 28.81 \\
Weight gain & 47.83 & 51.08 \\
Total Score & 13.99 & 15.72 \\
\hline
\end{tabular}

laryngectomy. But in advanced stages, the only treatment is total laryngectomy. Total laryngectomy is the gold standard for the treatment of advanced laryngeal cancer with large cartilage destruction, extra laryngeal extension, and treatment of recurrent laryngeal cancer after primary non-surgical treatment. ${ }^{7}$ Conform another study, our study shows that the number of men is more than women. ${ }^{8}$ Men are susceptible to laryngeal carcinoma due to several factors such as higher smoking habits and alcohol consumption. ${ }^{9}$ Smoking is known as the highest risk factor (99\%) occurrence of laryngeal carcinoma. Smoking components, especially nitrosamines and polycyclic aromatic hydrocarbons act as carcinogens in the laryngeal epithelium, these components specifically cause mutations in DNA and interfere with the normal cell division and proliferation process that triggers the mechanism of carcinogenesis. In addition to cigarettes, alcohol is also an important risk factor in the pathogenesis of laryngeal cancer. Chronic inflammation of the laryngeal layer of ethanol can cause a series of mutations at the gene level that interferes with cell proliferation and increase carcinogenesis. ${ }^{10}$

Older age is also a risk factor as confirmed in our study which is in the range of 56-65 years old. These results are in accordance with the study conducted elsewhere. ${ }^{12}$ The high number of malignancies in the elderly is caused by mutations that accumulate in the body resulting in less efficient deoxyribonucleic acid repair and reduced immune system that decreases defense against cancer cells. In the elderly, there is also the accumulation of cells undergoing the aging process and supporting the microenvironment of the development of cancer cells. ${ }^{12}$ Furthermore, the education level of the study subjects varied from elementary school to university with the highest level of education being senior high school. The level of education can be used as an indicator of the patient's socio-economic status. The majority of patients with laryngeal cancer are unemployed or unskilled workers. People with low socioeconomic levels tend to be more smoking and alcohol consumption, poor diet, lack of prevention strategies and poor 
sanitation and support high rates of laryngeal cancer in this population. ${ }^{13}$

Based on the SF-36 questionnaire, our study shows that the quality of life of patients with laryngeal cancer who have undergone total laryngectomy is generally good, which includes the physical and mental components. This result confirms, that the SF-36 quality of life scores is generally good on all scales $(>$ $60.5)$. The lowest average score on the SF-36 questionnaire is on the scale of perception of general health and the vitality scale. The quality of life, in general, is also affected by the quality of life of patients based on the functional capacity that changes due to illness. Functionally, there are speech disorders, such as difficulty speaking, changes in sound quality, speechlessness, delay in the sound coming out and a hoarse voice when speaking. There are other physical symptoms, such as phlegm, difficulty swallowing, eating difficulties, neck muscle weakness, and fungal infections. Psychologically, depression and regret can be found in patients undergoing laryngectomy. ${ }^{14}$

Interestingly, the pain scale score in EORTC QLQ-H \& N3 is low, which shows that most respondents do not complain of pain. To minimize bias, it is also necessary to pay attention to the scale of the use of the pain killer. In this study, the use of a pain killer is only found in a small portion ( 6 of 23 patients) which indicates that the possibility of postpain 3 months after surgery is no longer felt.

The component that also affects the quality of life of patients after laryngectomy is sound. Sound is one of the important components in communication which is the basic need of every human being in carrying out his life. Communication has an important role so it must be considered to be one of the important things in managing patients. ${ }^{2}$ The largest average value is found on the scale of speech problems represented by three questions, such as hoarseness, whether there are difficulties in talking to other people, and whether there are difficulties in talking on the telephone. The results of this study are in line with the study conducted by Akil et al. ${ }^{15}$ and Dinescu et al. ${ }^{16}$ There is a significant change in voice after total laryngectomy, and patients may experience difficulties in speech problems because the laryngeal function of speech is completely lost.

In post laringectomy patients have difficulty to communicate. Medical rehabilitation therapy has been done and patients are expected to speak again even without the vocal cords. Tracheo esophageal prosthesis (TEP) is the most common way to restore speech after laryngectomy. Sound prostheses are valves that make it possible to make sound by pushing air from the lungs through the valve and up to the mouth, using sound prostheses requires training and therapists. ${ }^{8}$ Tracheo esophageal prosthesis cannot be used optimally in countries with low socioeconomic status due to the difficulty of accessing health services that can carry out periodic prosthesis changes. Esophageal speech therapy (EST) is a natural, reliable and cost-effective method that can be applied without other devices or prosthesis. Esophageal speech therapy is a sound production method that involves esophageal oscillations, this is different from the production of sound in normal people who use vocal oscillations. The way to do EST is to swallow air into the esophagus which causes the esophagus to vibrate and then release it by controlling it to create a sound that is used to produce speech. ${ }^{17}$

Larynx plays a role in the process of swallowing so that the total laryngectomy procedure performed in patients with laryngeal carcinoma can also affect the ability to swallow. The radiation effect as adjuvant therapy can also contribute to the occurrence of dysphagia, dry mouth, and thick saliva. However, our study shows not many problems with swallowing, eating problems, problems opening wide mouths, dry mouth, and thick split. This is in line with the scale of using a feeding hose that no patient uses a feeding hose at all which shows the ability to swallow is still good, and thus it is estimated that food intake through the mouth is maintained well and no weight loss occurs. This result is also offset by an increase in body weight felt by some patients, in line with the study conducted by Akil et al..$^{15}$, showing that the scale of dry mouth and thick spit has a small score that indicates the small problem on that scale. Radiation therapy triggered xerostomia. Functional cells of the salivary gland such as excretory cells and acinar cells respond acutely to radiation. Tissues with low mitotic speeds should not be sensitive to radiation. The granulation hypothesis states that secretory granule membranes in acinar cells undergo lipid peroxidation damage triggered by radiation, and as a result, proteolytic enzymes begin to leak causing cell lysis. Another hypothesis states that at the beginning of radiation there is a disruption in cellular function due to damage to the selective membrane, disrupting signals that regulate water excretion, without being accompanied by cell death, while further damage is experienced due to the death of 
progenitor cells and stem cells. Saliva function will continue to be disturbed for several months after radiotherapy. All patients should be encouraged to take an active role in the management of their xerostomia; so a daily mouth examination, checking for red, white, or dark patches, ulcers, or tooth decay, is highly recommended. ${ }^{19}$

Dental problems are known to be a problem in patients with total laryngectomy. ${ }^{15}$ However, there is no dental problem found in the study or wide mouth opening problems, which are in accordance with other studies. ${ }^{16}$ The presence of sexual problems in laryngeal cancer patients after total laryngectomy occurs, ${ }^{15}$ due to decreased libido and due to decreased self-confidence, especially in women, however, some other studies show no sexuality problems. ${ }^{16,18}$ Cough problem showed a good quality of life and showed no significant coughing problems. These results are also supported by studies conducted by Akil et al. ${ }^{15}$ and Dinescu et al. ${ }^{16}$ also reported the existence of cough problems experienced by patients after laryngectomy.

The limitation of this study was there was no assessment of the quality of life before total laryngectomy was performed so that there was no known improvement in the quality of life before and after treatment in the form of total laryngectomy.

As a conclusion, the quality of life in patients with laryngeal carcinoma after total laryngectomy in Dr. Hasan Sadikin General Hospital Bandung is generally good based on the SF-36 generic questionnaire and EORTC QLQ-H \& N35specific questionnaire for head and neck cancer. Speech is the main problem and needs to be further elaborated to enhance the quality of life.

\section{References}

1. Kolegium Ilmu Kesehatan Telinga Hidung Tenggorokan Bedah Kepala Leher. Modul utama onkologi kepala leher.: Neoplasma laring, II ed. Jakarta: Kolegium Ilmu Kesehatan Telinga Hidung Tenggorokan Bedah Kepala Leher;2015.

2. Badwal JS. Quality of life following voice restoration with tracheoesophageal prosthesis after total laryngectomy. World Journal of Pharmaceutical and Medical Research. 2016;2(6):191-4.

3. Mansour MMH, Abdel-Aziz M, Saafan ME, Al-Afandi HRM, Darweesh M. Voice, swallowing, and quality of life after management of laryngeal cancer with different treatment modalities. The Egyptian Journal of Otolaryngology. 2016;32(1):37-44.

4. Perwitasari DA. Development the validation of Indonesian version of SF36 questionnaire in cancer disease. Indonesian J Pharm. 2012;23(4):248-53.

5. RAND Corporation. 36-item short form survey (SF-36) Scoring instructions. California: RAND Corporation; 2009.

6. Bjordal K, De Graeff A, Fayers PM, Hammerlid E, van Pottelsberghe C, Curran $D$, et al. A 12 country field study of the EORTC QLQ-C30 (version 3.0) and the head and neck cancer specific module (EORTC QLQ-H\&N35) in head and neck patients. EORTC Quality of Life Group. EurJ Cancer. 2000;36(14):1796-807.

7. Sheahan P. Management of advanced laryngeal cancer. Rambam Maimonides Med J. 2014;5(2):e0015.

8. Rossi VC, Fernandes FL, Ferreira MA, Bento LR, Pereira PS, Chone CT. Larynx cancer: quality of life and voice after treatment. Braz J Otorhinolaryngol. 2014;80(5):4038.

9. Tawab HMA, Abd ElMessih MW, AlNaggar NA, El Sharkawy LS, . Study of the epidemiology and management of laryngeal cancer in Kasr Al-Aini Hospital. The Egyptian Journal of Otolaryngology. 2014;30(3):208-14.

10. Cahyadi I, Permana AD, Dewi YA, Aroeman NA. Karakteristik penderita karsinoma laring di Departemen Ilmu Kesehatan Telinga Hidung Tenggorok Bedah Kepala Leher Rumah Sakit dr Hasan Sadikin Bandung periode Januari 2013-Juli 2015. Tunas Medika Jurnal Kedokteran \& Kesehatan. 2016;3(1):39-42.

11. Rahmaeni, Kuhuwael F, Rahardjo SP. Validitas dan reliabilitas EORTC QLQH\&N35 sebagai alat ukur kualitas hidup penderita kanker kepala leher. ORLI. 2015;45(2):142-50.

12. Putri SA, Dewi YA, Dewayani BM. Risk Factors of Laryngeal Carcinoma in Otorhinolaryngology-Head and Neck Division of Dr. Hasan Sadikin Hospital Bandung. Journal of Medicine and Health. 2018;2(2):715-21.

13. Markou K, Christoforidou A, Karasmanis I, Tsiropoulos G, Triaridis S, Constantinidis I, et al. Laryngeal cancer: epidemiological data from Northern Greece and review of the literature. Hippokratia. 2013;17(4): 313-8.

14. Noonan BJ, Hegarty J. The impact of total 
laryngectomy: the patient's perspective. Oncol Nurs Forum. 2010;37(3):293-301.

15. Akil F, Yollu U, Toprak SF, Ayral M. Laryngectomy: what is the impact of the type of surgery on life quality and sexual function? Acta Otorhinolaringol Ital. 2017;37(4):276-80.

16. Dinescu FV, Tiple C, Chirila M, Muresan R, Drugan T, Cosgarea M. Evaluation of health-related quality of life with EORTC QLQ-30 and QLQ-H\&N35 in Romanian laryngeal cancer patients. Eur Arch Othorhinolaryngol. 2016;273(9):273540.

17. Sahin M, Ogut MF, Vardar R, Kirazli T, Engin EZ, Bor S. Novel esophageal speech therapy method in total laryngectomized patients: biofeedback by intraesophageal impedance. Dis Esophagus. 2016;29(1):417.

18. Akduman D, Karaman M, Uslu C, Bilac O, Turk O, Deniz M, et al. Larynx cancer treatment results: survive and quality of life assessment. Kulak Burun Bogaz Ihtis Derg. 2010;20(1):25-32.

19. Pinna R, Campus G, Cumbo E, Mura I, Milia E. Xerostomia induced by radiotherapy: an overview of the physiopathology, clinical evidence, and management of the oral damage. Ther Clin Risk Manag. 2015;11:171-88. 